\title{
Current surgical techniques in the management of the symptomatic neonate with severe Ebstein anomaly: Too much, too little, or just enough?
}

Christopher J. Knott-Craig, MD, FACS, and Umar S. Boston, MD

\section{ABSTRACT}

The management of severely symptomatic neonates with Ebstein anomaly is challenging during the early neonatal period. Initial management goals should focus on mitigating a central shunt; providing respiratory mechanical support; providing an adequate but not excessive source of pulmonary blood flow; and minimizing pulmonary vascular resistance. For most patients thus stabilized, definitive repair should be prudently deferred until it is safe for a bailout bidirectional Glenn anastomosis to be added, usually at age 3 to 4 months. For those who remain critical, initial ligation of the large ductus and placing a more peripheral aortopulmonary shunt, or ligating the main pulmonary artery, should be weighed against a primary biventricular repair (Knott-Craig repair), or the Starnes' single-ventricle palliation. The Da Silva cone biventricular repair should generally be avoided during the early neonatal period. An initial Starnes' repair can be potentially converted to a biventricular repair in later infancy. (JTCVS Techniques 2021;9:128-34)

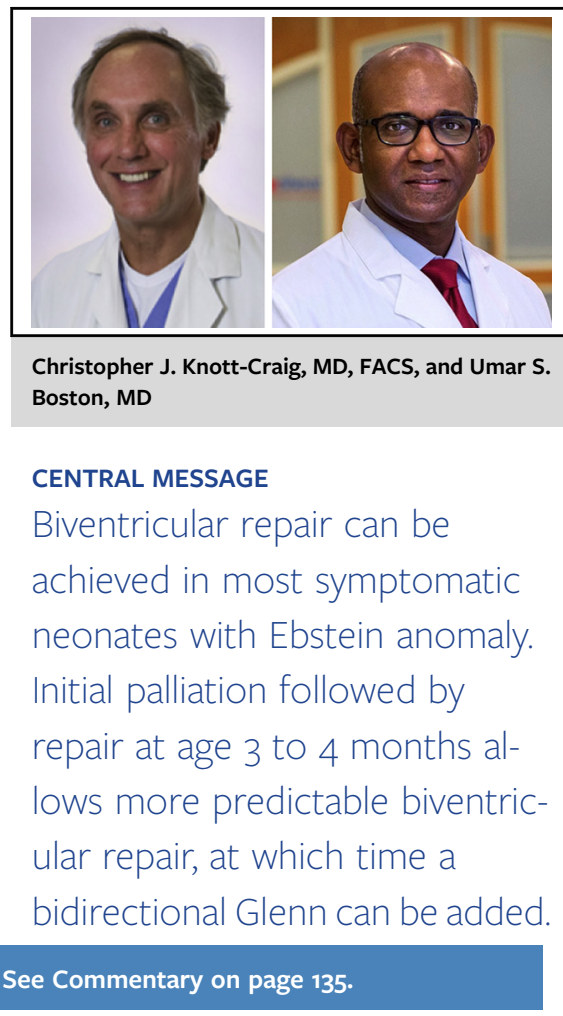

Feature Editor's Introduction-Ebstein anomaly is a rare and heterogeneous complex congenital cardiac malformation that affects the tricuspid valve and right ventricle. Clinical presentation varies based on the severity of tricuspid regurgitation, right ventricle size and function, and status of right ventricular outflow tract. At

\footnotetext{
From the Division of Pediatric Cardiovascular Surgery, Le Bonheur Children's Hospital and the University of Tennessee Health Sciences Center, Memphis, Tenn.

Received for publication March 19, 2021; accepted for publication May 11, 2021; available ahead of print Aug 14, 2021.

Address for reprints: Christopher J. Knott-Craig, MD, FACS, Division of Pediatric Cardiovascular Surgery, Le Bonheur Children's Hospital and the University of Tennessee Health Sciences Center, Suite 332 Physician office Building, 50 N Dunlap, Memphis, TN 38105 (E-mail: cknottcr@uthsc.edu).

JTCVS Techniques 2021;9:128-34

2666-2507

Copyright (c) 2021 The Author(s). Published by Elsevier Inc. on behalf of The American Association for Thoracic Surgery. This is an open access article under the CC BY-NC-ND license (http://creativecommons.org/licenses/by-nc-nd/4.0/).

https://doi.org/10.1016/j.xjtc.2021.05.030
}

the most extreme end of the spectrum, symptomatic neonates are most challenging and at highest risk for hospital mortality. There are wide variations in the treatment of symptomatic neonates and small infants among institutions. This is well demonstrated in a recent review of the Society of Thoracic Surgeons where the number of neonates treated averaged $<40$ yearly, and treatment strategies varied widely while showing persistently high operative mortality ( $>25 \%$ ).

Dr Christopher Knott-Craig has championed tricuspid valve repair in neonates and small infants with Ebstein anomaly and accumulated the largest experience. He has refined his strategy with time and demonstrated that valve repair can be successfully performed in various anatomic and clinical scenarios, including infants who have undergone prior single-ventricle palliation. Despite his encouraging results, neonatal tricuspid valve remains rare and reproducibility remains questionable. Additionally, many surgeons continue to believe that neonates who fail 
conservative medical treatment have severe anatomic and functional limitations of the right ventricle that would limit their ability to generate flow and therefore should undergo initial single-ventricle palliation.

Drs Knott-Craig and Boston provide an excellent review of their current management strategy of neonates and small infants with Ebstein anomaly and describe their management algorithm that determines timing and type of intervention based on anatomy and hemodynamic situation. They describe cases that they believe are amenable to conservative management, and those where modified BlalockTaussig shunt or initial single ventricle approach with the Starnes procedure are more appropriate.

I enjoyed learning from these doctors' experience in this challenging and rare patient population and I believe that readers will find this review inspiring and very educational.

\section{Bahaaldin Alsoufi, MD}

Ebstein anomaly (EA), a rare congenital heart defect, results from failure of delamination of the tricuspid valve (TV) from its respective endocardium. ${ }^{1}$ EA in symptomatic neonates is associated with a mortality ranging from $25 \%$ to $100 \%{ }^{2-6}$ As such, these neonates pose significant medical and surgical challenges.

Symptomatology in the neonatal period can be attributed to several issues:

- Severe tricuspid regurgitation associated with right ventricular dysfunction or hypoplasia may lead to severe cyanosis and low cardiac output;

- Anatomical pulmonary atresia or pulmonary stenosis, which is present in $50 \%$ of symptomatic neonates undergoing surgical intervention, ${ }^{7-9}$ or, similarly, functional pulmonary atresia can also be present when the pulmonary vascular resistance is high, and the right ventricle is dysfunctional and cannot generate antegrade flow across the pulmonary valve ${ }^{7-11}$; and finally and most catastrophically,

- A circular shunt may exist when there is severe pulmonary and tricuspid regurgitation present associated with a large patent ductus arteriosus. ${ }^{12,13}$

\section{ANATOMY OF EA}

The anatomy of EA in a symptomatic neonate is different from that of older patients who have survived into childhood or adulthood: Embryological failure of delamination leaves the TV leaflets tethered to the endocardium by fibromuscular attachments or foreshortened chordae. Leaflets are apically displaced with the septal leaflet most severely influenced followed by posterior then anterior leaflets. The anterior leaflet is often diminutive or scalloped in symptomatic neonates, and the leading edge may be partially or completely attached to the free wall of the right ventricle. In this situation, blood flows from the right atrium predominantly through the anteroseptal commissure into the diminutive functional infundibular chamber of the right ventricle. The slit-like opening of the TV is therefore at the 10 o'clock position as viewed by the surgeon. ${ }^{14,15}$ In this extreme form of EA (a biventricular repair is doomed to failure), the Starnes single-ventricle palliation ${ }^{16-18}$ may be the best option. In the less-severe spectrum of severe neonatal EA, as the anterior leaflet gets larger and more associated with partial or full delamination of the inferior leaflet, biventricular repair becomes more possible. ${ }^{4,5,7,14}$

Commonly associated cardiac defects that are apparent in neonates include pulmonary stenosis or pulmonary atresia, ${ }^{7,14,15,18}$ both anatomic and functional, and ventricular septal defect-in the latter the ventricular septal defect is covered by the septal leaflet of the TV, and the left ventricle ejects directly into the infundibular chamber and pulmonary valve through the anteroseptal commissure, maintaining the cardiac output and allowing surgery to be deferred for a few months.

\section{PATHOPHYSIOLOGY}

Neonates are symptomatic because of ineffective right ventricle cardiac output. This results from a combination of factors, including poor myocardial contractility, right ventricular dysfunction or hypoplasia, severe TV regurgitation, and impedance of antegrade pulmonary blood flow across the pulmonary valve either due to high pulmonary vascular resistance or due to the ductal blood flow being directed at the pulmonary valve with associated pulmonary regurgitation. Gross cardiomegaly is usually present, leading to compression of the lungs (Figure 1) and right or

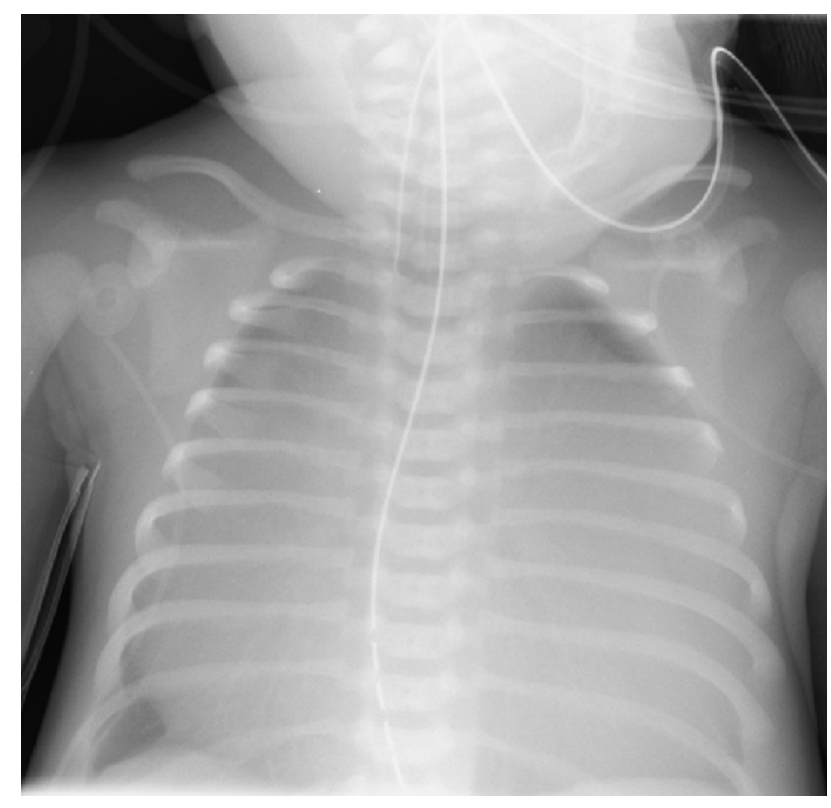

FIGURE 1. Chest radiograph demonstrating severe cardiomegaly in a newborn infant with Ebstein anomaly. 
left ventricular dysfunction. ${ }^{19,20}$ Cyanosis is usually present. As the pulmonary vascular resistance drops over the first weeks of life, the right ventricle may then be able to overcome the afterload to establish antegrade flow. True anatomical pulmonary atresia is seen in about $50 \%$ of symptomatic neonates with EA., 5,9

Pulmonary regurgitation represents the end-stage of right ventricular failure. A circular shunt is created with left-toright flow from aorta to pulmonary artery across the patent ductus arteriosus to the pulmonary artery. Flow reversal across the pulmonary valve into the right ventricle then occurs. This blood is then ejected into the right atrium due to tricuspid insufficiency and across the atrial septal defect to the left side of the heart and the aorta, to complete the circular shunt. Pancaking of the left ventricle cavity impedes filling and diminishes systemic cardiac output. ${ }^{16,19,20}$ Cardiogenic shock results.

In less-severe forms of EA, the right ventricle can generate effective antegrade flow, especially when the pulmonary vascular resistance decreases. Despite this, neonates with severe tricuspid regurgitation or gross cardiomegaly who are otherwise asymptomatic have an associated mortality of $45 \%$ within the first year of life without intervention. ${ }^{3,14,15}$ The natural history of being diagnosed with EA during the perinatal period is associated with a high mortality during infancy. ${ }^{2,3,7,10}$ Those who survive early childhood can expect reasonable longevity.

\section{ECHOCARDIOGRAPHY}

Echocardiography is the most important diagnostic test to confirm EA. From a surgical perspective, there are 2 echocardiographic views that we utilize to assess the feasibility of a biventricular repair; these are the apical 4-chamber and the parasternal short axis. The apical 4-chamber view allows assessment of leaflet anatomy and right ventricular function. From this view, EA is defined as apical displacement of the septal leaflet $\geq 8 \mathrm{~mm} / \mathrm{m}^{2} .{ }^{13,21}$ The parasternal short-axis view allows assessment of the right ventricular outflow tract. The regurgitant flow velocity across the tricuspid valve can give valuable additional information regarding the functional suitability of the right ventricle. ${ }^{11}$ The Great Ormond Street Echocardiogram (GOSE) score is a mortality risk stratification score for neonates with EA. It is calculated from the apical 4-chamber view by dividing the sum of the right atrium and atrialized right ventricular volumes by the sum of the functional right ventricular, left atrial, and left ventricular volumes (Figure 2). A GOSE score $>1.4$ (grade IV) is associated with a hospital mortality approximating $100 \%{ }^{3}$ (Table 1 ).

\section{TREATMENT}

\section{Medical}

Hospital mortality for medically treated somewhat-lesssymptomatic neonates with EA approximates $25 \% .^{2-5,7}$

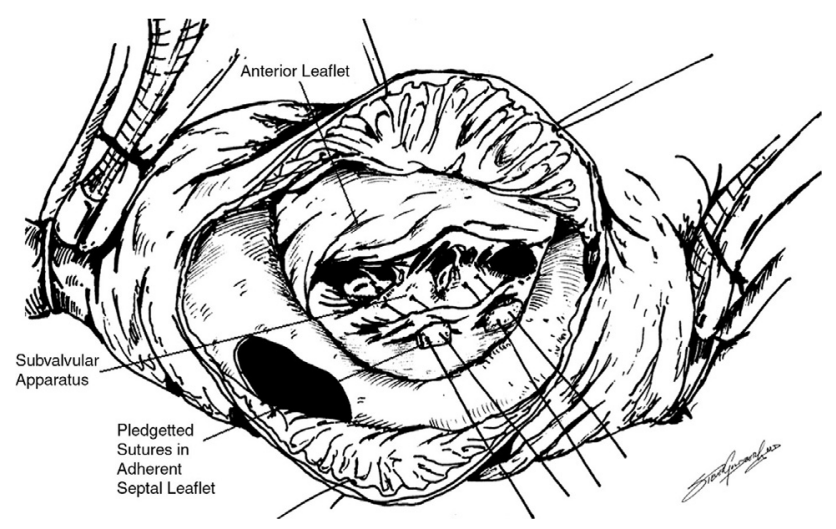

FIGURE 2. Sebening suture is demonstrated. A suture is passed from the dominant papillary muscle attached to the anterior leaflet and fixed to a point on the ventricular septum directly opposite to move the anterior leaflet to the septum, allowing for coaptation with the septum and/or posterior leaflet. Reprinted with permission from reference 15.

Furthermore, it has been shown that surgical mortality for EA during the neonatal period ranges from $27 \%$ to $53 \%$ depending on the procedure performed. ${ }^{4-6}$ Surgical mortality significantly improves to $<10 \%$ if the patient can be medically managed for a few months. ${ }^{7,14,22}$

Relatively stable patients can initially be treated with mechanical ventilation or supplemental oxygen, and prostaglandin infusion. The first test of adequacy of antegrade pulmonary blood flow comes upon spontaneous or iatrogenic ductal closure. The second test is whether the neonate can be safely weaned from the ventilator, and the third and final test is whether the neonate can tolerate full enteral feeds; quite often a neonate will survive the first 2 tests but die from aspiration or feeding intolerance when enteral feeds are introduced - surrogates for severe right heart failure. Generally, if a neonate gets to this point, he will be a good candidate for biventricular repair.

Patients with anatomical pulmonary atresia, particularly those with moderate or less tricuspid regurgitation, will require at a reliable source of pulmonary blood flow in the form of a surgically placed systemic-pulmonary shunt during the neonatal period. ${ }^{17,22,23}$

TABLE 1. Mortality prediction based on Great Ormond Street Echocardiography (GOSE) score*

\begin{tabular}{llc}
\hline & \multicolumn{2}{l}{ GOSE score } \\
\hline GOSE score & Ratio & Mortality \\
\hline I & $<0.5$ & $8 \%$ \\
II & $0.5-1.0$ & $8 \%$ \\
III (acyanotic) & $1.1-1.4$ & $10 \%$ early, $45 \%$ late \\
III (cyanotic) & $1.1-1.4$ & $100 \%$ \\
IV & $>1.5$ & $100 \%$ \\
\hline
\end{tabular}

*From: Celermajer DS, Bull C, Till JA, Cullen S, Vassillikos VP, Sullivan ID, et al. Ebstein's anomaly: presentation and outcome from fetus to adult. J Am Coll Cardiol. 1994:22:170-6. 
In critically unstable neonates, mitigating the effects of a circular shunt often very early in life is critically important; this can be mitigated with sedation, paralysis, inotropic support, and prostaglandin infusion; mechanical support with large $(10 \mathrm{~mL} / \mathrm{kg})$ tidal volumes and positive endexpiratory pressure are key to promoting adequate ventilation in patients with massive cardiomegaly causing lung compression. If cardiac output is still significantly compromised, an emergency Starnes' operation is the best option; in those in whom bypass needs to be postponed, initial ligation of the main pulmonary artery, or ligation of the ductus and addition of a more peripheral aortopulmonary shunt may be lifesaving. ${ }^{11,16,22,23}$

\section{Surgical Indications}

In the contemporary era, many neonates can be safely optimized without immediate surgical intervention. Those with persistent cyanosis (saturations $<75 \%$ ), those with severe right heart failure associated with moderate-to-severe tricuspid regurgitation will require early intervention; the neonates are usually ventilator-dependent with gross cardiomegaly and can be predicted to need early intervention by the GOSE score. ${ }^{3}$ A GOSE score $>1.4$ will usually need very early intervention ${ }^{3,5,7}$ (Table 1). Those with a GOSE score $>1.0$ and who are acyanotic should undergo repair before age 6 months.

\section{Surgical Procedures}

Over the past 30 years there has certainly been an evolution of surgical procedures for EA in neonates. $4,5,7,9,11,12$ The first series of survivors using a single-ventricle palliation strategy was that published by Starnes in $1991,{ }^{16}$ which included the first neonatal palliation from 1987. The technique was later refined to include division of the main pulmonary artery and inclusion of a fenestrated patch closure of the $\mathrm{TV}^{17,18}$ (Figure 3, $A$ and $B$ ) with an aortopulmonary shunt as source of pulmonary blood flow, and the early survival was around $81 \%$. This is best indicated for those with severe tricuspid regurgitation associated with pulmonary atresia, or those with clearly inadequate right ventricle or anterior leaflet of the TV; a marker for these circumstances includes a tricuspid regurgitation peak velocity flow $<2.0 \mathrm{~m} / \mathrm{s}$ (These patients subsequently will require further single-ventricle palliation with a bidirectional Glenn and Fontan procedures at around age 6 months and 3 years, respectively.) In 2014, Sano and colleagues ${ }^{24}$ added ventricular exclusion to the Starnes' palliation (with good results). In our opinion, this should be avoided in neonates.

In 1994, Knott-Craig and colleagues ${ }^{15}$ performed the first 3 successful biventricular repairs in neonates with EA. This series included a young infant in whom the Starnes' palliation was taken down and the patient was converted to a biventricular repair; she remains well more than 22 years later. The hospital survival was again around $80 \%$. This series was later updated to include 48 neonates and young infants, among whom 32 required surgery during the neonatal period with 16-year follow-up. ${ }^{7,8}$ The Knott-Craig repair was modeled after the technique advocated by Danielson and colleagues $^{21}$ at the Mayo Clinic. It is best performed in those with antegrade pulmonary blood flow or functional pulmonary atresia with an adequate anterior leaflet and right ventricle. The repair consists of creating a competent monocusp TV based on the anterior leaflet, a fenestrated atrial septal defect closure, reduction atrioplasty, and repair of all associated cardiac lesions ${ }^{7,8,14,15}$ (Figure 4, $A$ and $B$ ). It is essential that the leading edge of the anterior leaflet is not severely tethered to the free wall of the right ventricle. Although one can fenestrate the leading edge, this patient may be best suited for a Starnes' palliation during the neonatal period. If the anterior leaflet tissue is inadequate for successful coaptation with the septal annulus, a Sebening stitch $^{25}$ can be added (Figure 2). Associated anatomic pulmonary atresia is seen in approximately $60 \%$ of neonates with EA that we have treated. ${ }^{7,8}$ Based on our experience we now mostly choose to place a small right ventricle-pulmonary artery valved conduit. ${ }^{7,8,14}$

With the advent of the Da Silva cone repair for EA in children and adults, ${ }^{26}$ and the wide adoption of the cone

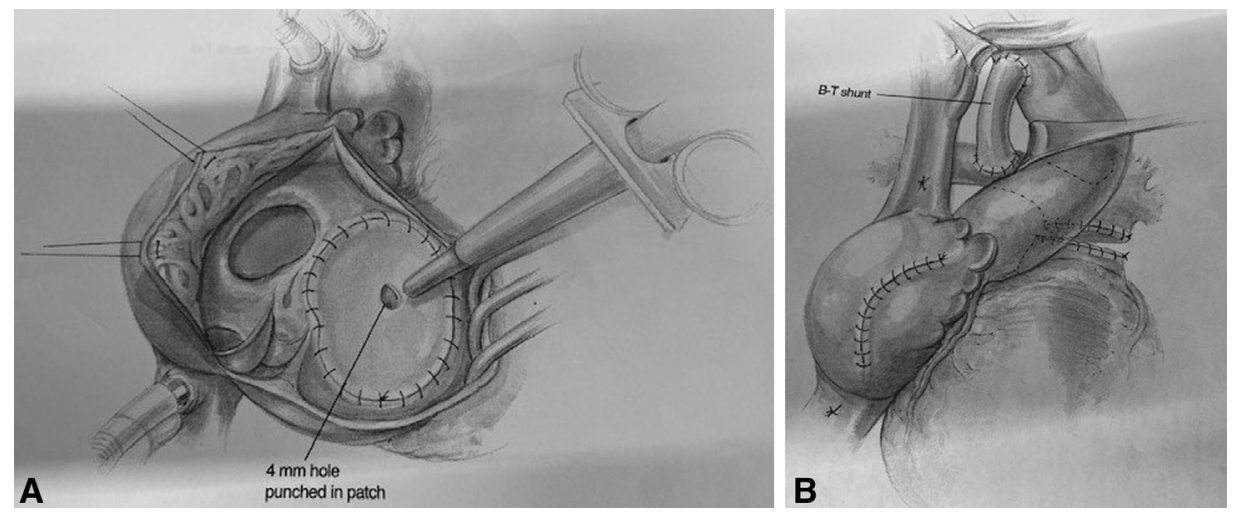

FIGURE 3. A and B, Starnes' single ventricle palliation. B-T shunt, Blalock-Taussig shunt. Reprinted from reference 9. 

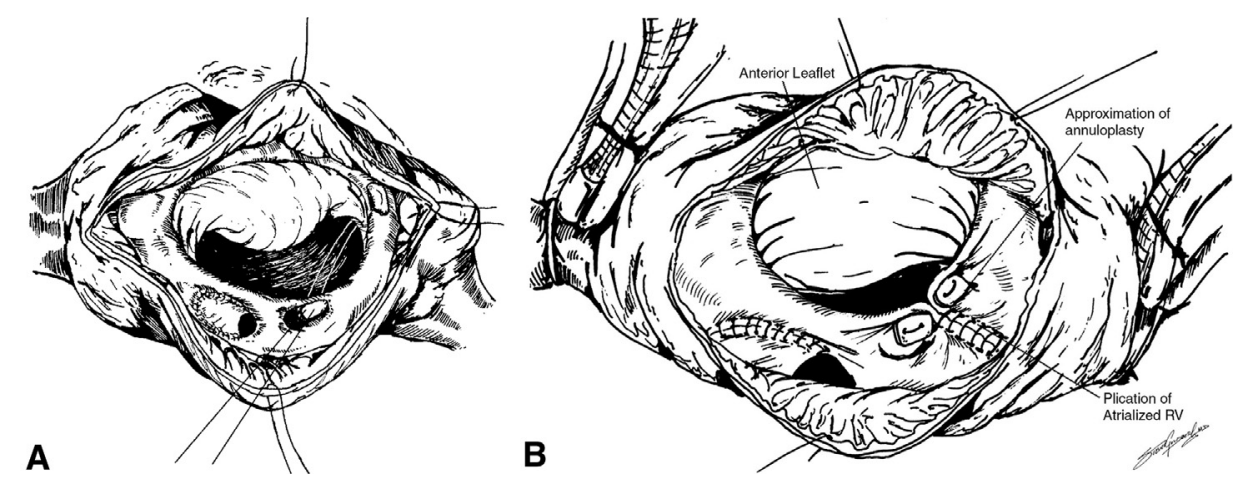

FIGURE 4. A and B, Knott-Craig monocusp repair based on the anterior leaflet. A double orifice tricuspid valve is created by passing a suture through the annulus at the anteroposterior commissure and then through the septal annulus adjacent to the coronary sinus. The posterior annulus and right ventricle $(R V)$ is then plicated. Reprinted with permission from reference 15.

repair for most older patients with EA, ${ }^{27,28}$ pediatric cardiac surgeons started exploring the possibility of using the cone repair in neonates mostly with only anecdotal success. ${ }^{11,12,29-31}$ In this operation, the leaflets of the TV are taken down from the annulus, further delaminated and sutured together to form a cone, and then reattached to the true annulus creating a trileaflet valve (Figure 5). Although attractive, this operation is best avoided in
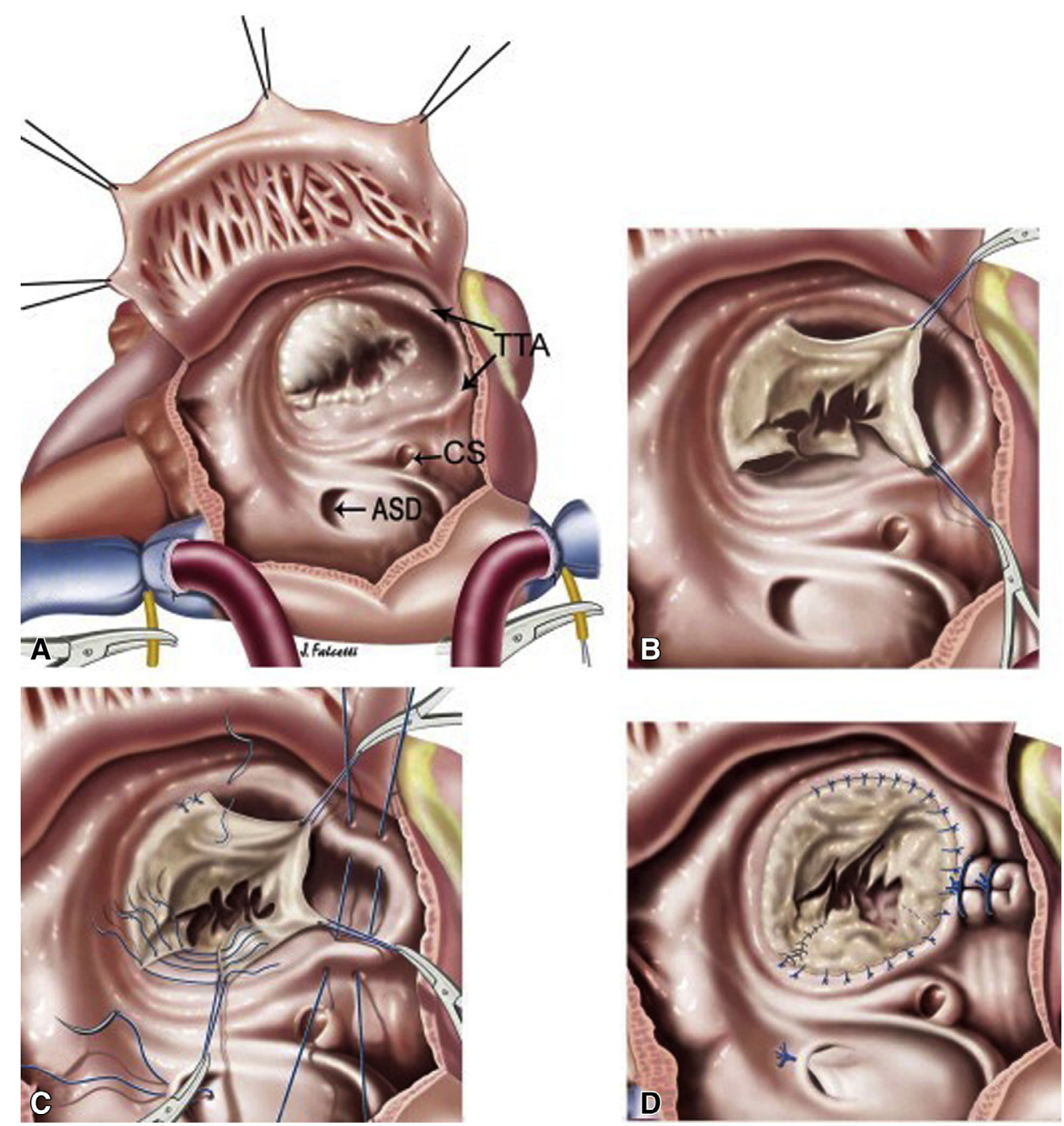

FIGURE 5. Da Silva cone operation. $T T A$, True tricuspid annulus; $C S$, coronary sinus; $A S D$, atrial septal defect. Reprinted with permission from reference 26. 


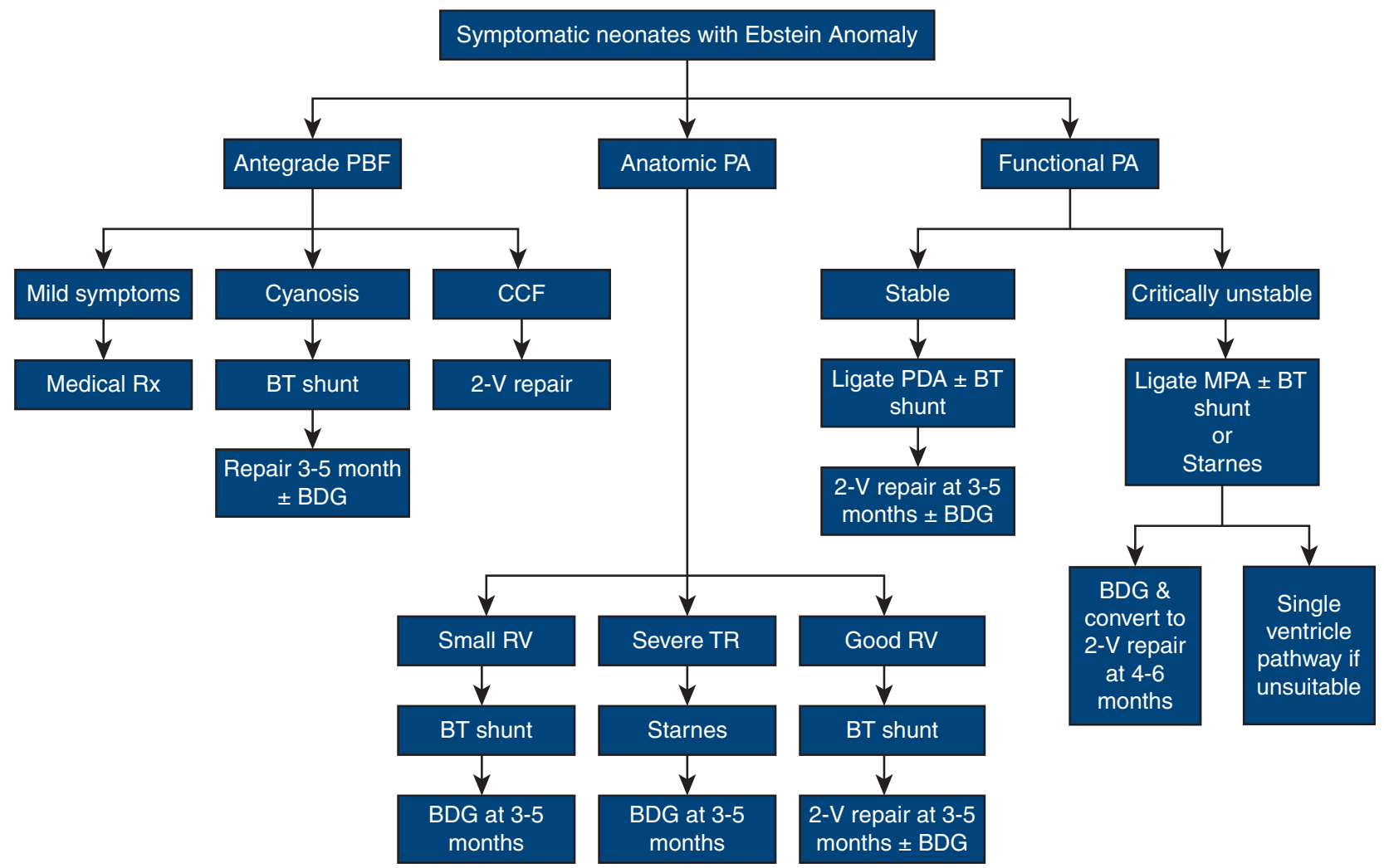

FIGURE 6. Algorithmic approach to the severely symptomatic neonate with Ebstein anomaly. $P B F$, Pulmonary blood flow; $P A$, pulmonary atresia; $C C F$, congestive cardiac failure; $B T$, Blalock-Taussig; $B D G$, Bidirectional GLenn; $R V$, right ventricle; $T R$, tricuspid regurgitation; $P D A$, patent ductus arteriosus; $M P A$, main pulomonary artery.

critically ill neonates (ie, it should only be attempted by those very experienced with the cone operation) Most recently, Da Silva and colleagues ${ }^{12}$ reported initially doing a Starnes' palliation followed by a conversion to a biventricular cone repair at neonate age around 4 to 6 months, similar to what we published 20 years earlier. ${ }^{14,15}$ Our personal bias is that if there is sufficient TV tissue to do a cone operation in a neonate, then that patient could most likely be managed medically and the surgery deferred until later.

Clearly, opinions differ strongly about the best strategy for the management of symptomatic neonates. $22,23,32,33$ with the consensus being that doing less early on is better, and that a biventricular repair is associated with better long-term outcomes and can ultimately be achieved in most patients. And if definitive surgery can be deferred for 3 to 5 months when a bidirectional Glenn can be safely added to the repair, then surgery should carry a very acceptable risk of $5 \%$ to $10 \% .^{7,15}$ In a recent analysis of current surgical practices in the management of EA in neonates in the United States, 34\% underwent TV repair, 27\% underwent isolated aortopulmonary shunt, and $20 \%$ underwent Starnes' palliation., ${ }^{4,5}$

Finally, the less-is-better-than-more approach is most appropriate for those patients with less-than-severe tricuspid regurgitation and predominantly cyanosis who are otherwise stable. In these patients, simply (ligating the ductus and) placing a modified Blalock-Taussig shunt makes perfect sense. ${ }^{5,18,22,23,33}$ During that operation, the right atrium can be plicated without the need for cardiopulmonary bypass. Definitive repair can then be deferred for 3 to 5 months, at which time biventricular repair is more predictable and associated with lower risk, predominantly because a bidirectional Glenn can be safely added. In the future, there is a possibility that this operation can be replaced with a ductal stent that includes a flow restrictor inside ${ }^{34}$ For those neonates critically unstable with a circular shunt, immediate Starnes' palliation or (emergency) ligation of the main pulmonary artery, or ligating the ductus and placing a more peripheral aortopulmonary shunt, may be lifesaving. ${ }^{35}$ Definitive palliation can be deferred for 7 to 10 days once the patient has stabilized. Our suggested algorithmic approach to symptomatic neonates is summarized in Table 1 and Figure 6.

The surgical strategy for symptomatic neonates with EA remains challenging and continues to evolve. Utilizing our algorithm, a biventricular repair can be achieved in most patients, either initially or as a staged operation. 


\section{Conflict of Interest Statement}

The authors reported no conflicts of interest.

The Journal policy requires editors and reviewers to disclose conflicts of interest and to decline handling or reviewing manuscripts for which they may have a conflict of interest. The editors and reviewers of this article have no conflicts of interest.

\section{References}

1. Ebstein W. Uber einen sehr seltenen fall von insufficienz der valvula tricuspidalis, bedingt durch eine angeborene hochgradige misshildung derselben. Arch Anat Physiol. 1866;33:238-54.

2. Freud LR, Escobar-Diaz MC, Kalish BT, Komarlu R, Puchalski MD, Jaeggi ET, et al. Outcomes and predictors of perinatal mortality in fetuses with Ebstein anomaly or tricuspid valve dysplasia in the current era a multicenter study. Circulation. 2015;132:481-9.

3. Celermajer DS, Cullen S, Sullivan ID, Spiegelhalter DJ, Wyse RKH, Deanfield JE. Outcome in neonates with Ebstein's anomaly. J Am Coll Cardiol. 1992;19:1041-6.

4. Holst KA, Dearani JA, Said SM, Davies RR, Pizarro C, Knott-Craig CJ, et al. Surgical management and outcomes of Ebstein anomaly in neonates and infants: a Society of Thoracic Surgeons congenital heart surgery database analysis. Ann Thorac Surg. 2018;106:785-91.

5. Davies RR, Pasquali SK, Jacobs ML. Current spectrum of surgical procedures performed for Ebstein's malformation: an analysis of the Society of Thoracic Surgeons congenital heart surgery database. Ann Thorac Surg. 2013;96: 1703-10.

6. Sarris GE, Giannopoulis NM, Tsoutsinos AJ, Chatzis AK, Kirvassilis G, Brawn WJ, et al. Results of surgery for Ebstein's anomaly: a multicenter study from the European Congenital Heart Surgeons Association. J Thorac Cardiovasc Surg. 2006;132:50-7.

7. Knott-Craig CJ, Goldberg SP, Ballweg JA, Boston US. Surgical decision making in neonatal Ebstein's anomaly: an algorithmic approach based on 48 consecutive neonates. World J Pediatr Cong Heart Surg. 2012;3:16-20.

8. Boston US, Goldberg SP, Ward KE, Overholt ED, Spentzas T, Chin TK, et al. Complete repair of Ebstein anomaly in neonates and young infants: a 16-year follow-up. J Thorac Cardiovasc Surg. 2011;141:1163-9.

9. Reemsten BL, Fagan BT, Wells WJ, Starnes VA. Current surgical therapy for Ebstein anomaly in neonates. J Thorac Cardiovasc Surg. 2006;132:1285-90.

10. Sata S, Murin P, Hraska V. Cone reconstruction of Ebstein's anomaly in a neonate. Ann Thorac Surg. 2012;94:e99-100.

11. Kajihara N, Asou Takeda Y, Yasui S, Kosaka Y, Onakatomi Y, Miyata D, et al. Rapid two-stage Starnes procedure for a symptomatic neonate with Ebstein anomaly. Ann Thorac Surg. 2010;90:2073-5.

12. Da Silva JP, Viegas M, Castro-Medina M, Da Silva LD. The Da Silva cone operation after the Starnes procedure for Ebstein's anomaly: new surgical strategy and initial results. J Thorac Cardiovasc Surg Tech. 2020;3:281-3.

13. Ho SY, Goltz D, McCarthy K, Cook AC, Connell MG, Smith A, et al. The atrioventricular junction in Ebstein malformation. Heart. 2000;83:444-9.

14. Goldberg SP, Jones RC, Boston US, Haddad L, Wetzel GT, Knott-Craig CJ, et al. Current trends in the management of neonates with Ebstein's anomaly. World $J$ Pediatr Congenit Heart Surg. 2011;2:554-7.

15. Knott-Craig CJ, Overholt ED, Ward KE, Ringewald JM, Baker SS, Razook JD. Repair of Ebstein's anomaly in the symptomatic neonate: an evolution of technique with 7-year follow-up. Ann Thorac Surg. 2002;73:1786-92.

16. Starnes VA, Pitlick PT, Bernstein D, Griffin ML, Choy M, Shumway NE. Ebstein's anomaly appearing in the neonate: a new surgical approach. J Thorac Cardiovasc Surg. 1991;101:1082-7.
17. Reemsten BL, Starnes VA. Fenestrated right ventricular exclusion (Starnes' procedure) for severe neonatal Ebstein anomaly. Available at: https://www. optechtcs.com/article/S1522-2942(08)00030-5/pdf. Accessed August 18, 2021.

18. Kumar SR, Kung G, Noh N, Castillo N, Fagan B, Wells WJ, et al. Single-ventricle outcomes after neonatal palliation of severe Ebstein anomaly with modified Starnes procedure. Circulation. 2016;134:1257-64.

19. Attenhofer Jost CH, Connolly HM, O’Leary PW, Warnes CA, Tajik AJ, Seward JB, et al. Left heart lesions in patients with Ebstein anomaly. Mayo Clin Proc. 2005;80:361-8.

20. Pignatelli RH, Texter KM, Denfield SW, Grenier MA, Altman CA, Ayres NA, et al. LV noncompaction in Ebstein's anomaly in infants and outcomes. JACC Cardiovasc Imaging. 2014;7:207-9.

21. Danielson GK, Maloney JD, Devloo RA. Surgical repair of Ebstein's anomaly. Mayo Clin Proc. 1979;54:185-92.

22. Luxford JC, Arora N, Ayer JG, Verrall CE, Cole AD, Orr Y, et al. Neonatal Ebstein anomaly: a 30 year institutional review. Semin Thorac Surg. 2017;29: 206-12.

23. Bove EL, Hirsch JC, Ohye RG, Devaney EJ. How I manage neonatal Ebstein's anomaly. Sem Thorac Cardiovasc Surg Ann. 2009;63-5.

24. Sano S, Fujii Y, Kasahara S, Kuroko Y, Tateishi A, Yoshizumi K, et al. Repair of Ebstein's anomaly in neonates and small infants: impact of ventricular exclusion and it indications. Eur J Cardiothorac Surg. 2014;4:549-55.

25. Augustin N, Schmidt-Habelmann P, Wottke M, Meisner H, Sebening F. Results after surgical repair of Ebstein's anomaly. Ann Thorac Surg. 1997;63: 1650-6.

26. da Silva JP, Baumgratz JF, da Fonseca L, Franchi SM, Lopes LM, Tavares GM, et al. The cone reconstruction of the tricuspid valve in Ebstein's anomaly. The operation: early and midterm results. J Thorac Cardiovasc Surg. 2007;133: 215-23.

27. Dearani J, Bacha E, da Silva JP. Cone reconstruction of the tricuspid valve for Ebstein's anomaly: anatomic repair. Oper Tech Thorac Cardiovasc Surg. 2008; 13:109-25.

28. Dearani JA, Said SM, O'Leary PW, Burkhart HM, Barnes RD, Cetta F. Anatomic repair of Ebstein's malformation: lessons learned with the cone reconstruction. Ann Thorac Surg. 2013;95:220-6.

29. Bautista-Rodriquez C, Fraisse A, Burmester M, Ghez O. Cone reconstruction is feasible in babies under $2 \mathrm{~kg}$ of weight. Interact Cardiovasc Thorac Surg. 2019; 29:652-3.

30. Mizuno M, Hoashi T, Sakaguchi H, Kagisaki K, Kitano M, Kurosaki K, et al. Application of cone reconstruction for neonatal Ebstein anomaly or tricuspid valve dysplasia. Ann Thorac Surg. 2016;101:1811-7.

31. Huang SC, Wu ET, Chen SJ, Huang CH, Shih JC, Chou HW, et al. Surgical strategy toward biventricular repair for severe Exstein anomaly in neonates and infancy. Ann Thorac Surg. 2017; 104:917-25.

32. Vouhe P. Management of neonatal Ebstein's anomaly: towards a rational approach? Eur J Cardiothorac Surg. 2014;45:556.

33. Shinkawa T, Polimenakos AC, Gomez-Fifer CA, Charpie JR, Hirsch JC, Devaney EJ, et al. Management and long-term outcome of neonatal Ebstein's anomaly. J Thorac Cardiovasc Surg. 2010;139:354-8.

34. Kiene AM, Waller BR, Knott-Craig CJ, Sathanandam S. Percutaneous stage 1 palliation for hypoplastic left heart syndrome. Ann Thorac Surg. February 16, 2021.

35. Freud LR, McElhinney DB, Kalish BT, Escobar-Diaz MC, Komarlu R, Puchalski MD, et al. Risk factors for mortality and circulatory outcome among neonates prenatally diagnosed with Ebstein anomaly or tricuspid valve dysplasia: a multicenter study. J Am Heart Assoc. 2020;9:e016684.

Key Words: Ebstein anomaly, symptomatic neonates, surgical management 